\title{
Caco-2 Monolayer Permeability and Stability of Chamaelirium luteum (False Unicorn) Open-Chain Steroidal Saponins
}

\author{
Tegan P. Stockdale, ${ }^{\#}$ Victoria L. Challinor,,${ }^{\#}$ Reginald P. Lehmann, ${ }^{\perp}$ James J. De Voss, ${ }^{\#}$
}

Joanne T. Blanchfield ${ }^{\# *}$

${ }^{\#}$ School of Chemistry and Molecular Biosciences, University of Queensland, St. Lucia, Brisbane Australia 4072

${ }^{\perp}$ Integria Healthcare, Eight Mile Plains, Qld, Australia, 4113

\section{Supplementary information}

Table S1: ${ }^{1} \mathrm{H}$ NMR Data for the Aglycone of Compounds 1-4 (500 MHz).

Table S2: ${ }^{1} \mathrm{H}$ NMR Data for the Aglycone of Compounds 5-7 (500 MHz).

Table S3: ${ }^{1} \mathrm{H}$ NMR Data for the Sugar Units of Compounds 1-2, 4 and 6-7 (500 MHz).

Figure S1: Fraction transferred vs time (min) for the replicate wells in the apical to basal (AB) Caco-2 permeability of Chamaeliroside A (1).

Figure S2: Fraction transferred vs time ( $\mathrm{min}$ ) for the replicate wells in the basal to apical (BA) Caco-2 permeability of Chamaeliroside A (1).

Figure S3: Fraction transferred vs time (min) for the replicate wells in the A-B Caco-2 permeability of Chamaeliroside B (2).

Figure S4: Fraction transferred vs time $(\mathrm{min})$ for the replicate wells in the A-B Caco-2 permeability of Chiograsterol B (3).

Figure S5: Fraction transferred vs time $(\min )$ for the replicate wells in the A-B Caco-2 permeability of Heloside A (4).

Figure S6: Fraction transferred vs time $(\min )$ for the replicate wells in the B-A Caco-2 permeability of Heloside A (4).

Figure S7: Fraction transferred vs time (min) for the replicate wells in the A-B Caco-2 permeability of Helogenin (5).

Figure S8: Fraction transferred vs time $(\mathrm{min})$ for the replicate wells in the A-B Caco-2 permeability of 6-Dehydrochamaeliroside A (6).

Figure S9: Fraction transferred vs time $(\mathrm{min})$ for the replicate wells in the B-A Caco-2 permeability of 6-Dehydrochamaeliroside A (6).

Figure S10: Fraction transferred vs time $(\mathrm{min})$ for the replicate wells in the A-B Caco-2 permeability of 6-Dehydrochamaeliroside B (6).

Figure S11: Fraction transferred vs time (min) for the replicate wells in the A-B Caco-2 permeability of Chamaeliroside E (7).

Figure S12: Fraction transferred vs time (min) for the replicate wells in the A-B Caco-2 permeability of Propranolol assay 1.

Figure S13: Fraction transferred vs time (min) for the replicate wells in the A-B Caco-2 permeability of Propranolol assay 2.

Figure S14: Fraction transferred vs time $(\mathrm{min})$ for the replicate wells in the B-A Caco-2 permeability of Propranolol assay 2.

Figure S15: Fraction transferred vs time (min) for the replicate wells in the A-B Caco-2 permeability of Fluorescein assay 1.

Figure S16: Fraction transferred vs time (min) for the replicate wells in the A-B Caco-2 permeability of Fluorescein assay 2. 
Table S1: ${ }^{1} \mathrm{H}$ NMR Data for the Aglycone of Compounds 1-4 (500 MHz).

\begin{tabular}{|c|c|c|c|c|}
\hline & $\begin{array}{c}\text { Chamaeliroside A (1) } \\
{ }^{1} \mathrm{H}(\delta, \text { mult., } \mathrm{J}(\mathrm{Hz}) \\
\end{array}$ & $\begin{array}{c}\text { Chamaeliroside B (2) } \\
{ }^{1} \mathrm{H}(\delta, \text { mult., } \mathrm{J}(\mathrm{Hz}) \\
\end{array}$ & $\begin{array}{c}\text { Chiograsterol B (3) } \\
{ }^{1} \mathrm{H}(\delta, \text { mult., } \mathrm{J}(\mathrm{Hz}) \\
\end{array}$ & $\begin{array}{c}\text { Heloside A (4) } \\
{ }^{1} \mathrm{H}(\delta, \text { mult., J }(\mathrm{Hz})\end{array}$ \\
\hline $1 \alpha$ & $1.02, \mathrm{~m}$ & $1.02, \mathrm{~m}$ & $1.06, \mathrm{~m}^{a}$ & $1.36, \mathrm{td},(4.4,14.3)$ \\
\hline $1 \beta$ & 1.63, br d, $(12.6)$ & 1.62, br d, (12.7) & $1.71, \mathrm{dt},(3.4,13.0)$ & $3.22, \mathrm{dt},(3.1,14.0)$ \\
\hline $2 \alpha$ & $2.20, \mathrm{~m}$ & $2.20, \mathrm{~m}$ & $2.11, \mathrm{~m}^{a}$ & $2.15, \mathrm{~m}$ \\
\hline $2 \beta$ & $1.80, \mathrm{~m}$ & $1.80, \mathrm{~m}$ & $1.84, \mathrm{~m}^{a}$ & $1.91, \mathrm{~m}^{a}$ \\
\hline 3 & $4.19, \mathrm{~m}^{a}$ & $4.19, \mathrm{~m}^{a}$ & $3.86, \mathrm{~m}^{c}$ & $4.02, \mathrm{~m}^{a}$ \\
\hline $4 \alpha$ & $2.10, \mathrm{~m}^{a}$ & $2.11, \mathrm{~m}^{a}$ & $2.03, \mathrm{~m}^{a}$ & 2.78, ddd,$(1.9,4.7,13.3)$ \\
\hline $4 \beta$ & $2.28, \mathrm{~m}^{a}$ & $2.28, \mathrm{~m}^{a}$ & $2.41, \mathrm{~m}^{a}$ & $2.58, \mathrm{~m}^{a}$ \\
\hline 5 & $1.09, \mathrm{~m}^{a}$ & $1.09, \mathrm{~m}^{a}$ & $1.25, \mathrm{~m}^{a}$ & \\
\hline 6 & $3.95, \mathrm{~m}^{a}$ & $3.96, \mathrm{~m}^{a}$ & $4.04, \mathrm{~m}$ & $5.42, \mathrm{~d},(5.4)$ \\
\hline $7 \alpha$ & $1.18, \mathrm{~m}^{a}$ & $1.17, \mathrm{~m}^{a}$ & $1.25, \mathrm{~m}^{a}$ & $1.60, \mathrm{~m}^{a}$ \\
\hline $7 \beta$ & $2.03, \mathrm{dt},(2.9,13.5)$ & $2.02, \mathrm{dt},(2.9,13.3)$ & $2.08, \mathrm{~m}^{a}$ & $1.93, \mathrm{~m}^{a}$ \\
\hline 8 & $2.12, \mathrm{~m}^{a}$ & $2.12, \mathrm{~m}^{a}$ & $2.19, \mathrm{~m}$ & $1.53, \mathrm{~m}^{a}$ \\
\hline 9 & $0.67, \mathrm{td},(4.4,11.2)$ & $0.66, \mathrm{td},(4.6,11.1)$ & $0.75, \mathrm{td},(4.0,11.6)$ & $1.28, \mathrm{~m}^{a}$ \\
\hline $11 \mathrm{a}, \mathrm{b}$ & $1.42, \mathrm{~m}^{a}$ & $1.43, \mathrm{~m}^{a}$ & $1.52, \mathrm{~m}^{a}$ & $4.31, \mathrm{~m}^{a}$ \\
\hline $12 \alpha$ & $1.06, \mathrm{~m}^{a}$ & $1.07, \mathrm{~m}^{a}$ & $1.17, \mathrm{~m}^{a}$ & $1.58, \mathrm{~m}^{a}$ \\
\hline $12 \beta$ & 1.96, br d, (12.0) & 1.96, br d, (13.7) & $2.03, \mathrm{~m}^{a}$ & $2.61, \mathrm{dd},(4.5,12.0)$ \\
\hline 14 & $0.89, \mathrm{~m}$ & $0.88, \mathrm{~m}$ & $0.97, \mathrm{~m}$ & $1.08, \mathrm{~m}$ \\
\hline $15 \alpha$ & $2.29, \mathrm{~m}^{a}$ & $2.26, \mathrm{~m}^{a}$ & $2.32, \mathrm{dt},(7.4,12.6)$ & $2.27, \mathrm{dt},(7.6,12.8)$ \\
\hline $15 \beta$ & $1.47, \mathrm{td},(4.6,13.4)$ & $1.44, \mathrm{td},(3.9,13.2)$ & $1.48, \mathrm{td},(4.9,13.2)$ & $1.50, \mathrm{td}(4.4,13.0)$ \\
\hline 16 & $4.64, \mathrm{~m}$ & $4.62, \mathrm{~m}$ & $4.63, \mathrm{~m}$ & $4.76, \mathrm{~m}$ \\
\hline 17 & $1.12, \mathrm{~m}^{a}$ & $1.08, \mathrm{~m}^{a}$ & $1.16, \mathrm{~m}^{a}$ & $1.72, \mathrm{dd},(7.4,11.2)$ \\
\hline 18 & $1.07, \mathrm{~s}$ & $1.06, \mathrm{~s}$ & $1.11, \mathrm{~s}$ & $1.22, \mathrm{~s}$ \\
\hline 19 & $1.27, \mathrm{~s}$ & $1.27, \mathrm{~s}$ & $1.39, \mathrm{~s}$ & $1.27, \mathrm{~s}$ \\
\hline 20 & $2.54, \mathrm{~m}$ & $2.52, \mathrm{~m}$ & $2.55, \mathrm{~m}$ & $2.54, \mathrm{~m}^{a}$ \\
\hline 21 & $1.19, \mathrm{~d},(6.6)$ & $1.14, \mathrm{~d},(6.5)$ & $1.20, \mathrm{~d},(7.1)$ & $1.18, \mathrm{~d},(7.0)$ \\
\hline $22 \mathrm{a}$ & $1.89, \mathrm{dd},(8.9,13.7)$ & $1.66, \mathrm{dd}(8.9,13.5)$ & $1.89, \mathrm{dd},(8.6,13.2)$ & \multirow[t]{2}{*}{$4.15, \mathrm{~m}$} \\
\hline $22 b$ & $2.11, \mathrm{dd},(10.4,13.9)$ & $2.28, \mathrm{~m}^{a}$ & $2.10, \mathrm{~m}^{a}$ & \\
\hline $23 a, b$ & $4.07, \mathrm{~m}$ & $4.17, \mathrm{~m}^{a}$ & 4.08, br dd, $(5.3,10.3)$ & $1.74, \mathrm{~m}^{a}$ \\
\hline $24 \mathrm{a}$ & \multirow[t]{2}{*}{$3.67, q,(3.5)$} & \multirow[t]{2}{*}{$3.77, \mathrm{~m}^{a}$} & \multirow[t]{2}{*}{$3.67, \mathrm{dd},(5.2,11.3)^{d}$} & $2.07, \mathrm{~m}$ \\
\hline $24 \mathrm{~b}$ & & & & $1.30, \mathrm{~m}^{a}$ \\
\hline 25 & $2.38, \mathrm{~m}$ & $2.11, \mathrm{~m}^{a}$ & $2.36, \mathrm{~m}$ & $1.96, \mathrm{~m}$ \\
\hline $26 \mathrm{a}$ & \multirow[t]{2}{*}{$1.15, \mathrm{~d},(6.9)^{b}$} & \multirow[t]{2}{*}{$1.08, \mathrm{~d},(6.8)^{b}$} & \multirow[t]{2}{*}{$1.15, \mathrm{~d},(6.8)^{b}$} & $3.92, \mathrm{dd},(7.0,9.4)$ \\
\hline $26 \mathrm{~b}$ & & & & $3.61, \mathrm{dd},(5.9,9.5)$ \\
\hline 27 & $1.26, \mathrm{~d},(7.3)^{b}$ & $1.29, \mathrm{~d},(6.7)^{b}$ & $1.26, \mathrm{~d},(6.7)^{b}$ & $0.99, \mathrm{~d},(6.7)$ \\
\hline
\end{tabular}

${ }^{a}$ indicates overlapping signals. ${ }^{b}$ assignments interchangeable within column. ${ }^{b}$ interchangeable within column. ${ }^{c}$ differs from reported literature value $(3.98$, tt $(4.9,11.0)) .{ }^{7}$ coupling differs from reported literature values $(3.66, \mathrm{dd},(4.66 .5))^{7}$ 
Table S2: ${ }^{1} \mathrm{H}$ NMR Data for the Aglycone of Compounds 5-7 (500 MHz).

\begin{tabular}{|c|c|c|c|}
\hline & $\begin{array}{c}\text { Helogenin (5) } \\
{ }^{1} \mathrm{H}(\delta, \text { mult., J }(\mathrm{Hz})\end{array}$ & $\begin{array}{c}\text { 6-Dehydrochamaeliroside A (6) } \\
{ }^{1} \mathrm{H}(\delta, \text { mult., } \mathrm{J}(\mathrm{Hz})\end{array}$ & $\begin{array}{c}\text { 6-Dehydrochamaeliroside B (7) } \\
{ }^{1} \mathrm{H}(\delta \text {, mult., } \mathrm{J}(\mathrm{Hz})\end{array}$ \\
\hline $1 \alpha$ & $1.51, \mathrm{dt},(3.8,13.8)$ & $1.61, \mathrm{~m}^{a}$ & $1.18, \mathrm{~m}^{a}$ \\
\hline $1 \beta$ & $3.30, \mathrm{dt},(3.4,13.9)$ & $1.21, \mathrm{~m}^{a}$ & $1.57, \mathrm{~m}^{a}$ \\
\hline $2 \alpha$ & $2.13, \mathrm{~m}$ & $2.16, \mathrm{~m}^{a}$ & $2.16, \mathrm{~m}$ \\
\hline $2 \beta$ & $1.96, \mathrm{~m}^{a}$ & $1.62, \mathrm{~m}^{a}$ & $1.59, \mathrm{~m}^{a}$ \\
\hline 3 & $3.91, \mathrm{qt},(4.9,10.3)$ & $4.07, \mathrm{~m}^{a}$ & $4.05, \mathrm{~m}^{a}$ \\
\hline $4 \alpha$ & $2.70, \mathrm{~m}^{a}$ & $2.38, \mathrm{~m}^{a}$ & 2.38, br d, (12.7) \\
\hline $4 \beta$ & & $1.72, \mathrm{~m}^{a}$ & $1.73, \mathrm{~m}^{a}$ \\
\hline 5 & & $2.16, \mathrm{~m}^{a}$ & $2.16, \mathrm{~m}$ \\
\hline 6 & $5.50, \mathrm{~d},(5.5)$ & & \\
\hline $7 \alpha$ & $1.66, \mathrm{~m}^{a}$ & $1.97, \mathrm{t},(12.7)$ & $1.97, \mathrm{t},(12.8)$ \\
\hline $7 \beta$ & $2.00, \mathrm{~m}^{a}$ & $2.35, \mathrm{~m}^{a}$ & $2.33, \mathrm{dd},(4.5,13.0)$ \\
\hline 8 & $1.62, \mathrm{~m}^{a}$ & $1.78, \mathrm{~m}^{a}$ & $1.78, \mathrm{~m}^{a}$ \\
\hline 9 & 1.36, br t, $(10.3)$ & $1.12, \mathrm{~m}^{a}$ & $1.10, \mathrm{~m}^{a}$ \\
\hline $11 \mathrm{a}$ & $4.37, \mathrm{ddt}(5.6,10.4,10.4)$ & $1.42, \mathrm{~m}^{a}$ & $1.19, \mathrm{~m}^{a}$ \\
\hline $11 \mathrm{~b}$ & $1.61, \mathrm{~m}^{a}$ & $1.21, \mathrm{~m}^{a}$ & $1.40, \mathrm{~m}$ \\
\hline $12 \alpha$ & $2.64, \mathrm{dd},(4.7,12.0)$ & $1.90, \mathrm{~m}^{a}$ & $1.03, \mathrm{~m}^{a}$ \\
\hline $12 \beta$ & $1.12, \mathrm{~m}^{a}$ & $1.03, \mathrm{~m}^{a}$ & $1.88, \mathrm{~m}$ \\
\hline 14 & $2.29, \mathrm{dt}(7.6,12.8)$ & $0.96, \mathrm{~m}^{a}$ & $0.93, \mathrm{~m}^{a}$ \\
\hline $15 \alpha$ & $1.53, \mathrm{dt},(4.2,13.2)$ & $2.09, \mathrm{~m}^{a}$ & $2.06, \mathrm{dt},(7.3,12.7)$ \\
\hline $15 \beta$ & $4.77, \mathrm{tt},(4.3,7.3)$ & $1.35, \mathrm{td},(4.6,13.3)$ & $1.32, \mathrm{td},(4.9,13.1)$ \\
\hline 16 & $1.74, \mathrm{dd},(7.0,11.1)$ & $4.57, \mathrm{~m}$ & $4.55, \mathrm{~m}$ \\
\hline 17 & $1.25, \mathrm{~s}$ & $1.09, \mathrm{~m}^{a}$ & $1.03, \mathrm{~m}^{a}$ \\
\hline 18 & $1.41, \mathrm{~s}$ & $0.96, \mathrm{~s}$ & $0.93, \mathrm{~s}$ \\
\hline 19 & $2.61, \mathrm{~m}^{a}$ & $0.64, \mathrm{~s}$ & $0.63, \mathrm{~s}$ \\
\hline 20 & $1.20, \mathrm{~d},(7.1)$ & $2.53, \mathrm{~m}$ & $2.49, \mathrm{~m}$ \\
\hline 21 & $4.21, \mathrm{~m}$ & $1.17, \mathrm{~d},(6.6)$ & $1.11, \mathrm{~d},(6.6)$ \\
\hline $22 a$ & & $1.88, \mathrm{~m}^{a}$ & $1.65, \mathrm{~m}$ \\
\hline $22 b$ & $1.84, \mathrm{~m}^{a}$ & $2.09, \mathrm{~m}^{a}$ & $2.25, \mathrm{dd},(11.5,13.9)$ \\
\hline $23 a$ & $2.20, \mathrm{~m}^{a}$ & $4.08, \mathrm{~m}^{a}$ & $4.16, \mathrm{~m}$ \\
\hline $23 b$ & $1.39, \mathrm{~m}^{a}$ & & \\
\hline 24 & $1.92, \mathrm{~m}^{a}$ & $3.68, \mathrm{~m}$ & $3.76, \mathrm{~m}^{a}$ \\
\hline 25 & $3.78, \mathrm{~m}$ & $2.37, \mathrm{~m}^{a}$ & $2.09, \mathrm{~m}$ \\
\hline $26 a$ & $3.68, \mathrm{~m}$ & $1.15, \mathrm{~d},(6.9)^{c}$ & $1.07, \mathrm{~d},(6.9)^{c}$ \\
\hline $26 \mathrm{~b}$ & $1.09, \mathrm{~d},(6.7)$ & & \\
\hline 27 & & $1.26, \mathrm{~d},(6.7)^{c}$ & $1.27, \mathrm{~d},(6.7)^{c}$ \\
\hline
\end{tabular}


${ }^{a}$ indicates overlapping signals. ${ }^{b}$ appears as br d, but has the shape of a dt, which could be resolved under a stronger magnetic field. ${ }^{c}$ assignments interchangeable within column. ${ }^{c}$ differs from reported literature value $(0.61$, td $(4.1,10.9)) .{ }^{6} d$ complex splitting - appears to be singlet with fine splitting into dt, but only the br $\mathrm{d}$ splitting $(\mathrm{J}=5.3$ $\mathrm{Hz})$ can be peak picked, this indicates that the methine proton interacts differently with each adjacent methylene proton. 
Table S3: ${ }^{1} \mathrm{H}$ NMR Data for the Sugar Units of Compounds 1-2, 4 and 6-7 (500 MHz).

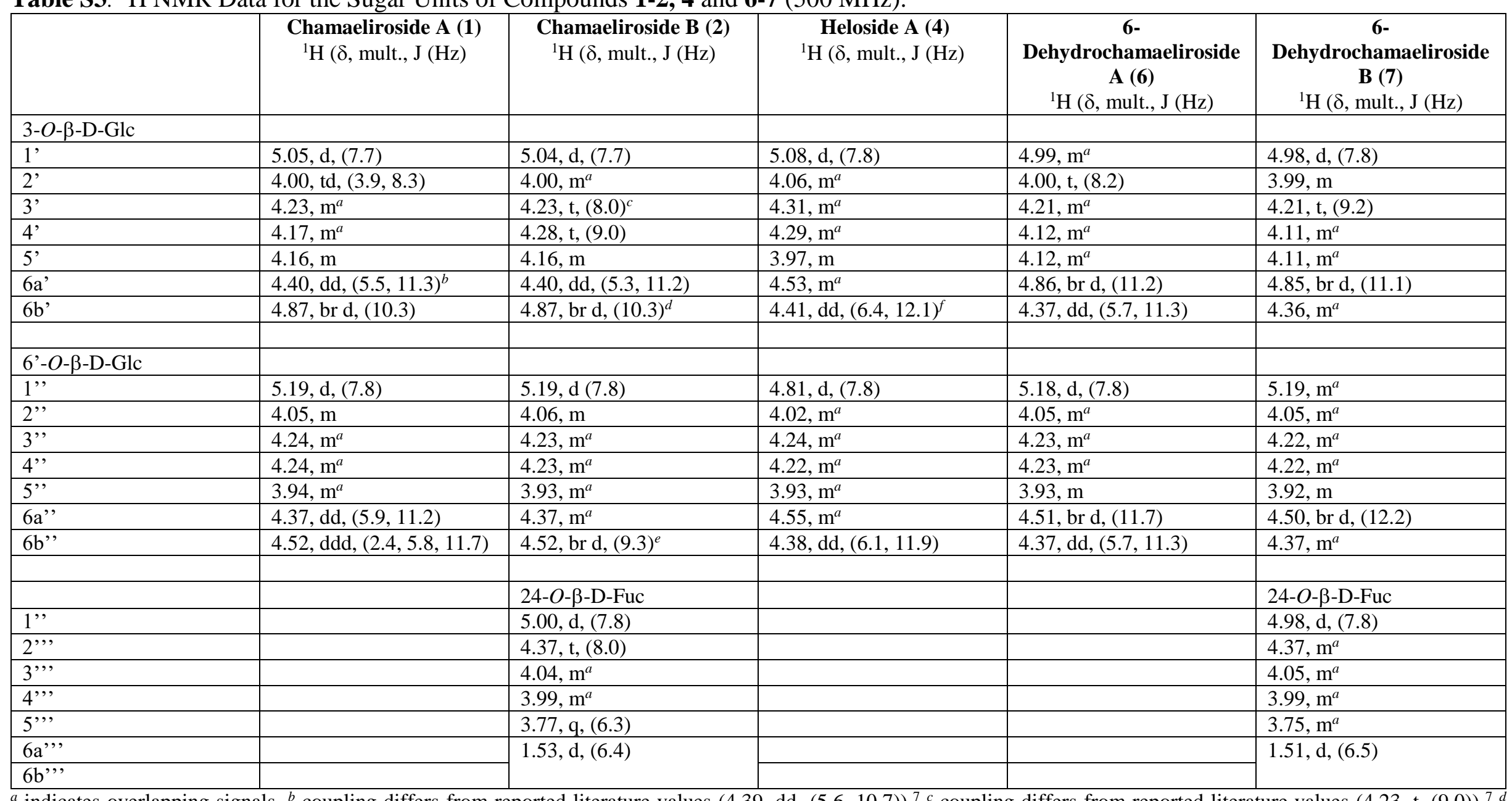

${ }^{a}$ indicates overlapping signals. ${ }^{b}$ coupling differs from reported literature values $(4.39, \mathrm{dd},(5.6,10.7)) .{ }^{c}{ }^{c}$ coupling differs from reported literature values $(4.23, \mathrm{t},(9.0)) .{ }^{7}$ coupling differs from reported literature values $(4.86$, br $\mathrm{d},(11.4)) .{ }^{7 e}$ coupling differs from reported literature values $(4.51$, br $\mathrm{d},(11.8)) .{ }^{7 f}$ coupling 


\section{Caco-2 in vitro permeability data}

Figure S1: Fraction transferred vs time (min) for the replicate wells in the apical to basal (A-

B) Caco-2 permeability of Chamaeliroside A (1)

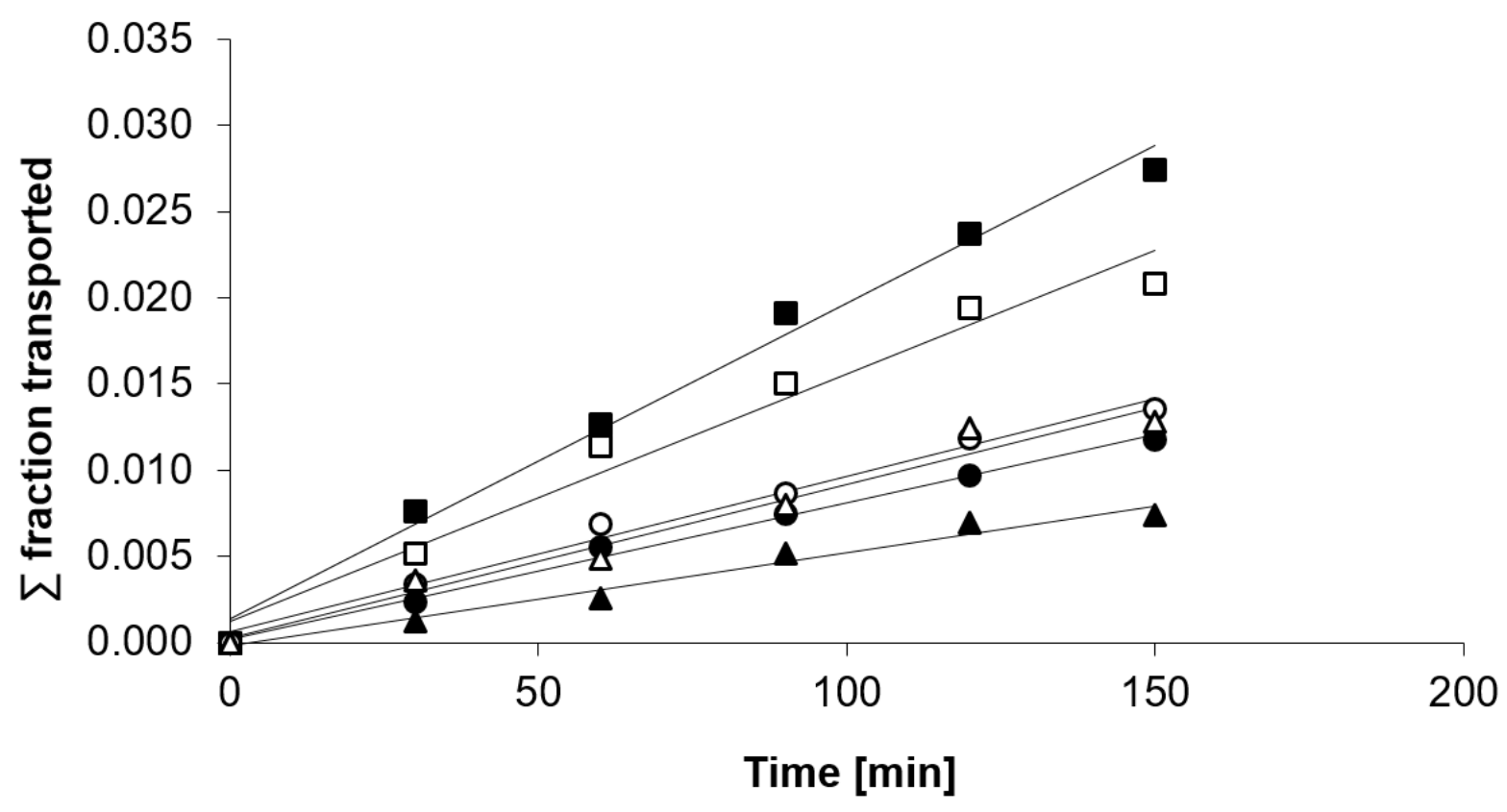

Figure S2: Fraction transferred vs time ( $\mathrm{min}$ ) for the replicate wells in the basal to apical (BA) Caco-2 permeability of Chamaeliroside A (1)

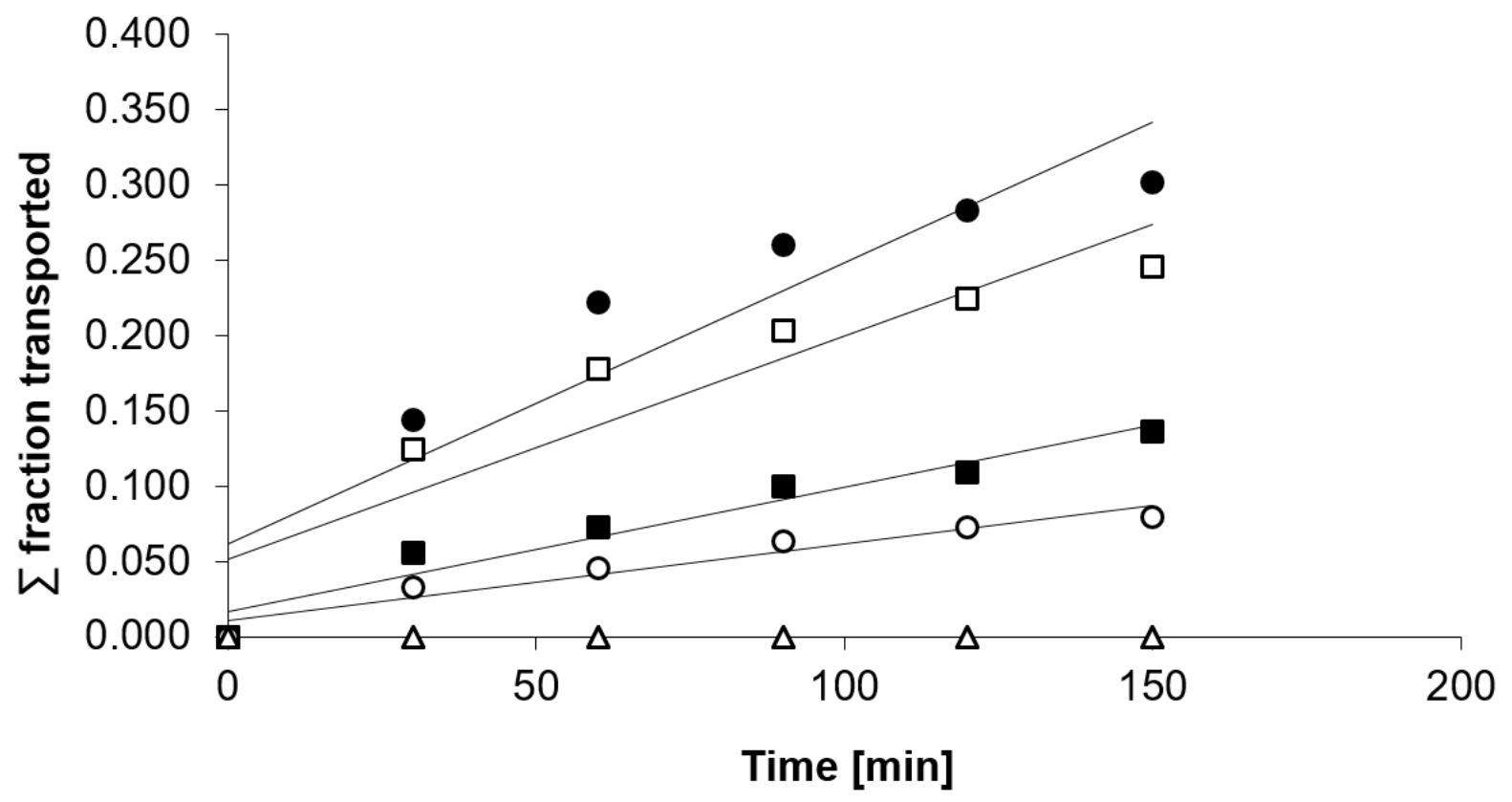


Figure S3: Fraction transferred vs time (min) for the replicate wells in the A-B Caco-2 permeability of Chamaeliroside B (2).

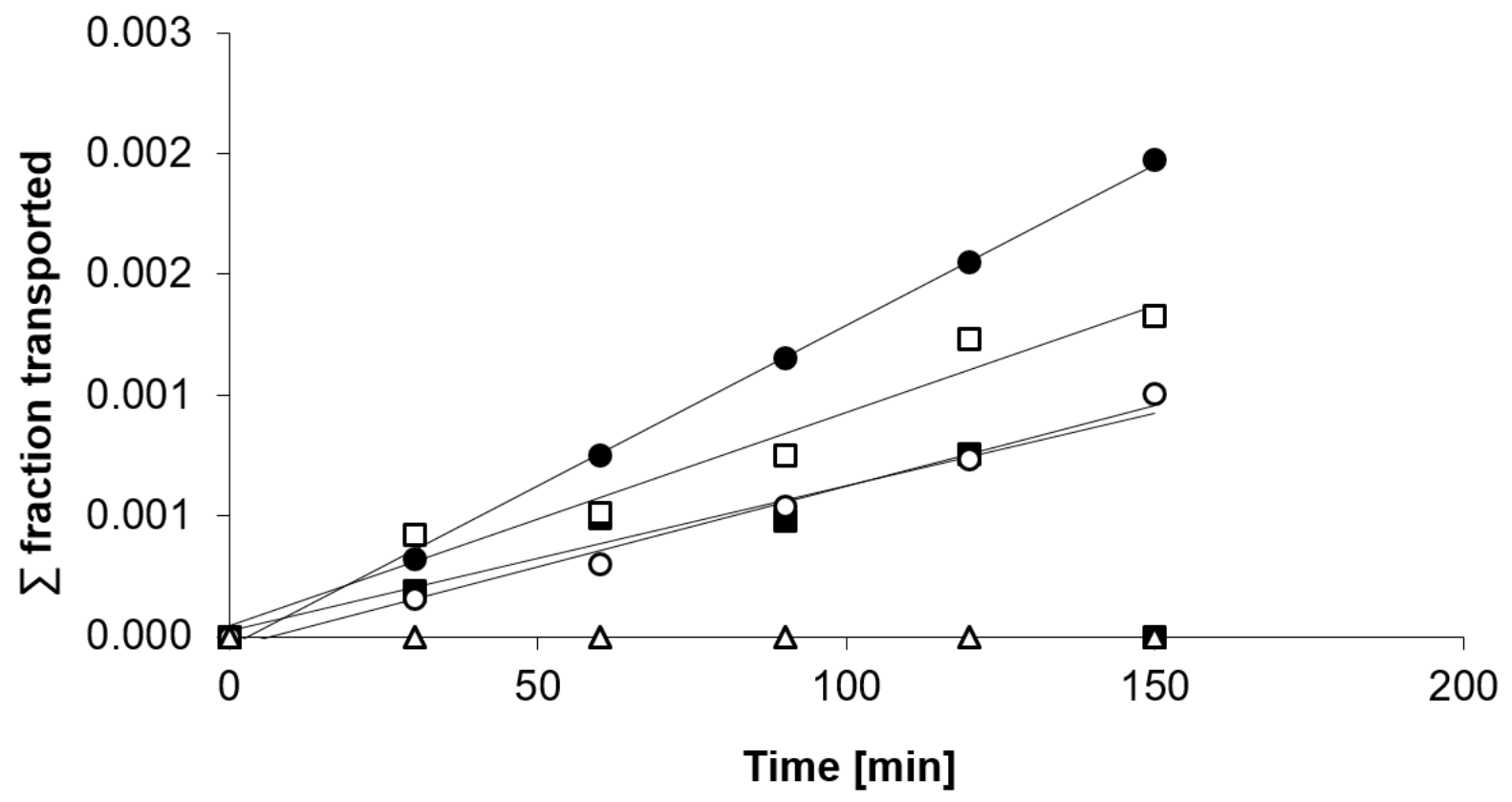

Figure S4: Fraction transferred vs time $(\min )$ for the replicate wells in the A-B Caco-2 permeability of Chiograsterol B (3).

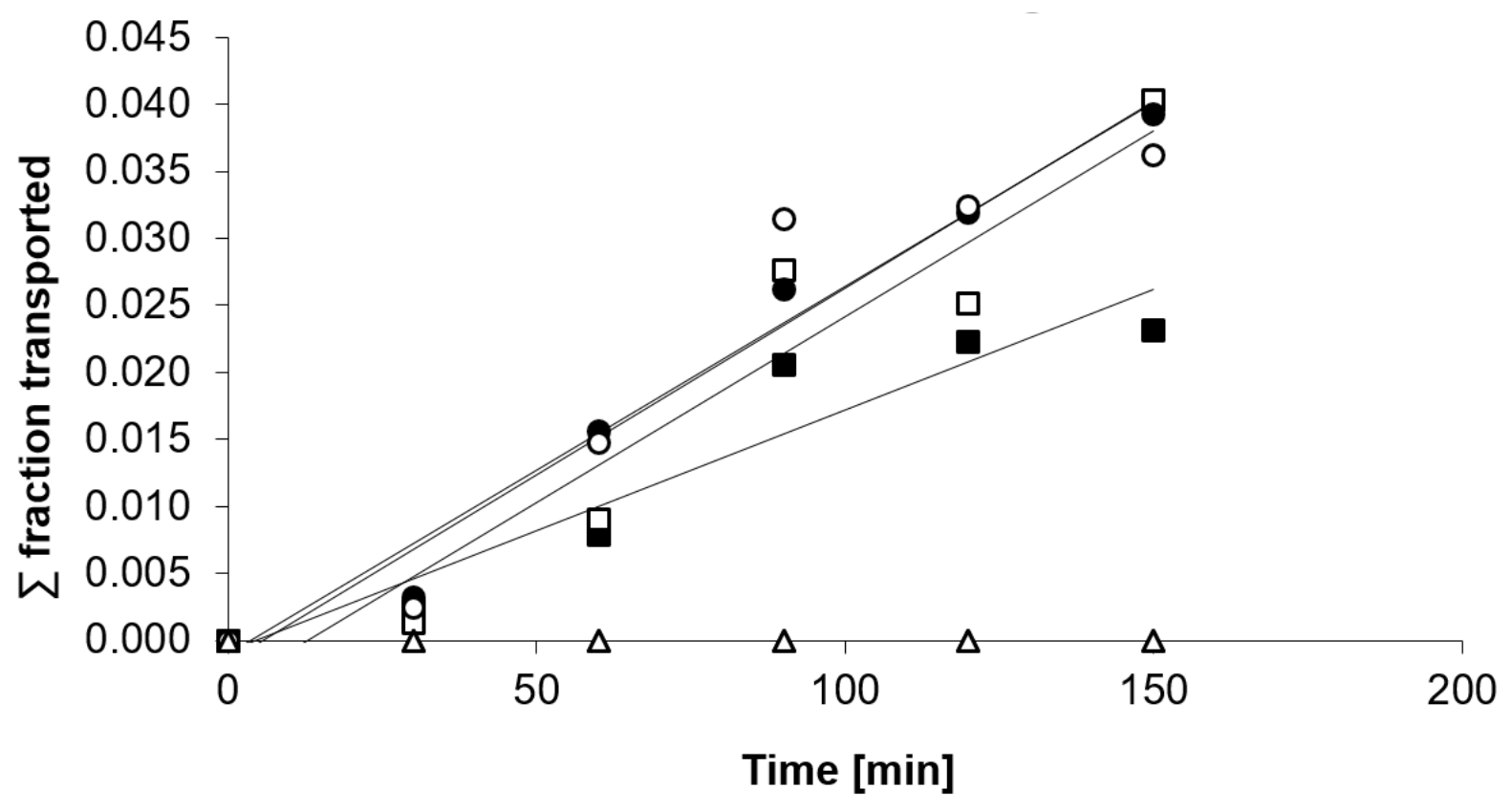


Figure S5: Fraction transferred vs time $(\mathrm{min})$ for the replicate wells in the A-B Caco-2 permeability of Heloside A (4)

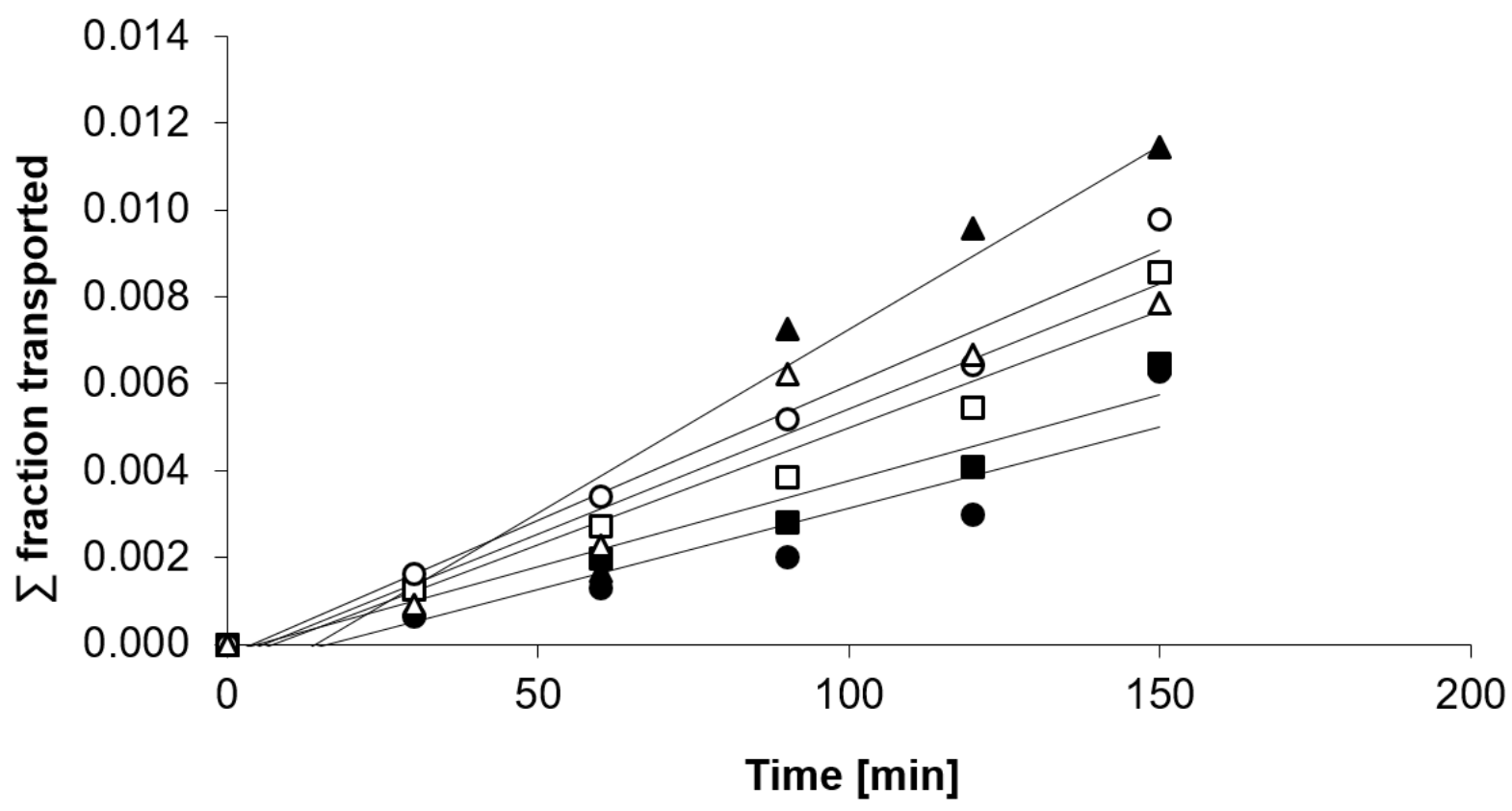

Figure S6: Fraction transferred vs time $(\min )$ for the replicate wells in the B-A Caco-2 permeability of Heloside A (4).

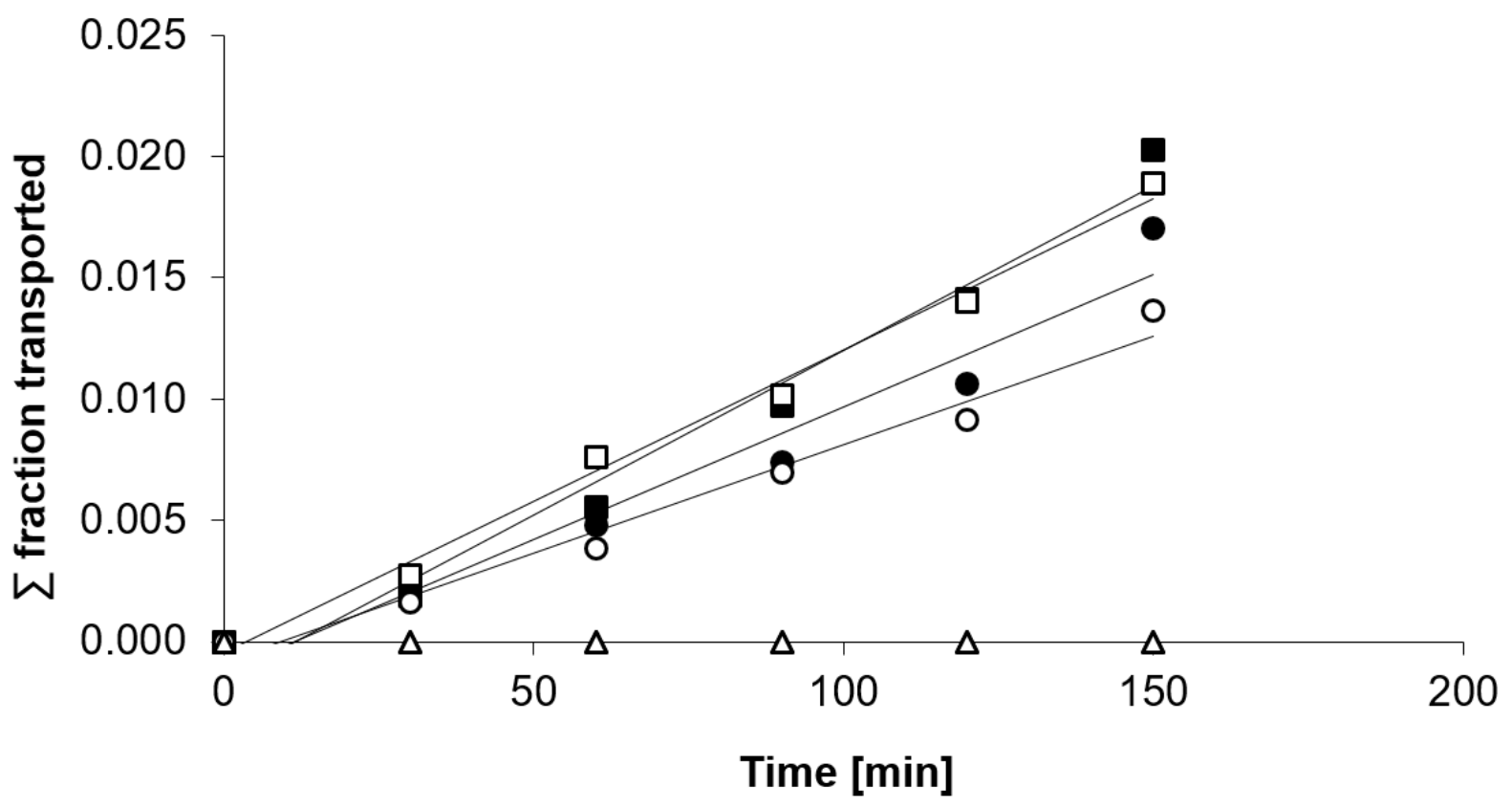


Figure S7: Fraction transferred vs time (min) for the replicate wells in the A-B Caco-2 permeability of Helogenin (5).

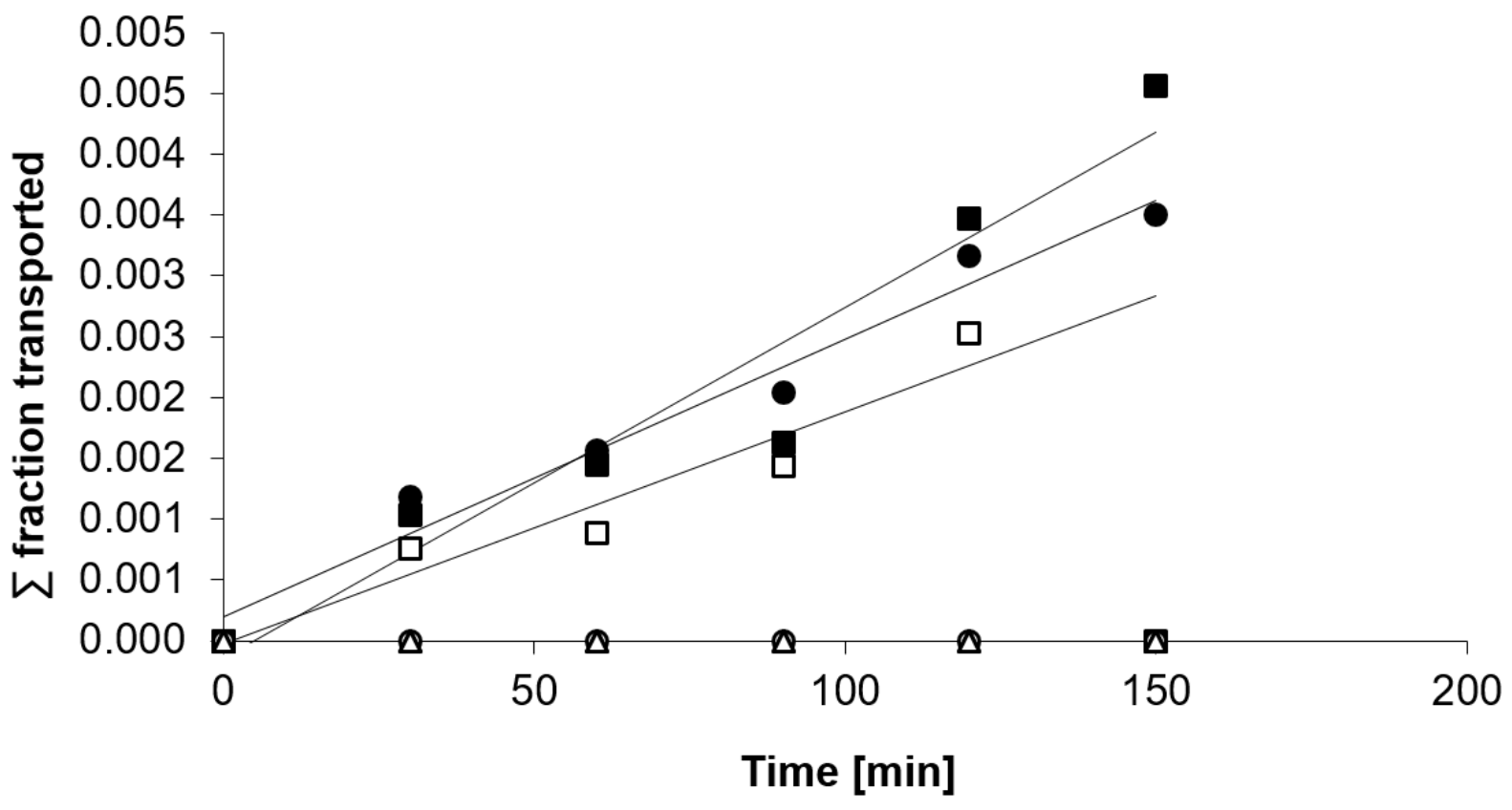

Figure S8: Fraction transferred vs time $(\min )$ for the replicate wells in the A-B Caco-2 permeability of 6-Dehydrochamaeliroside A (6).

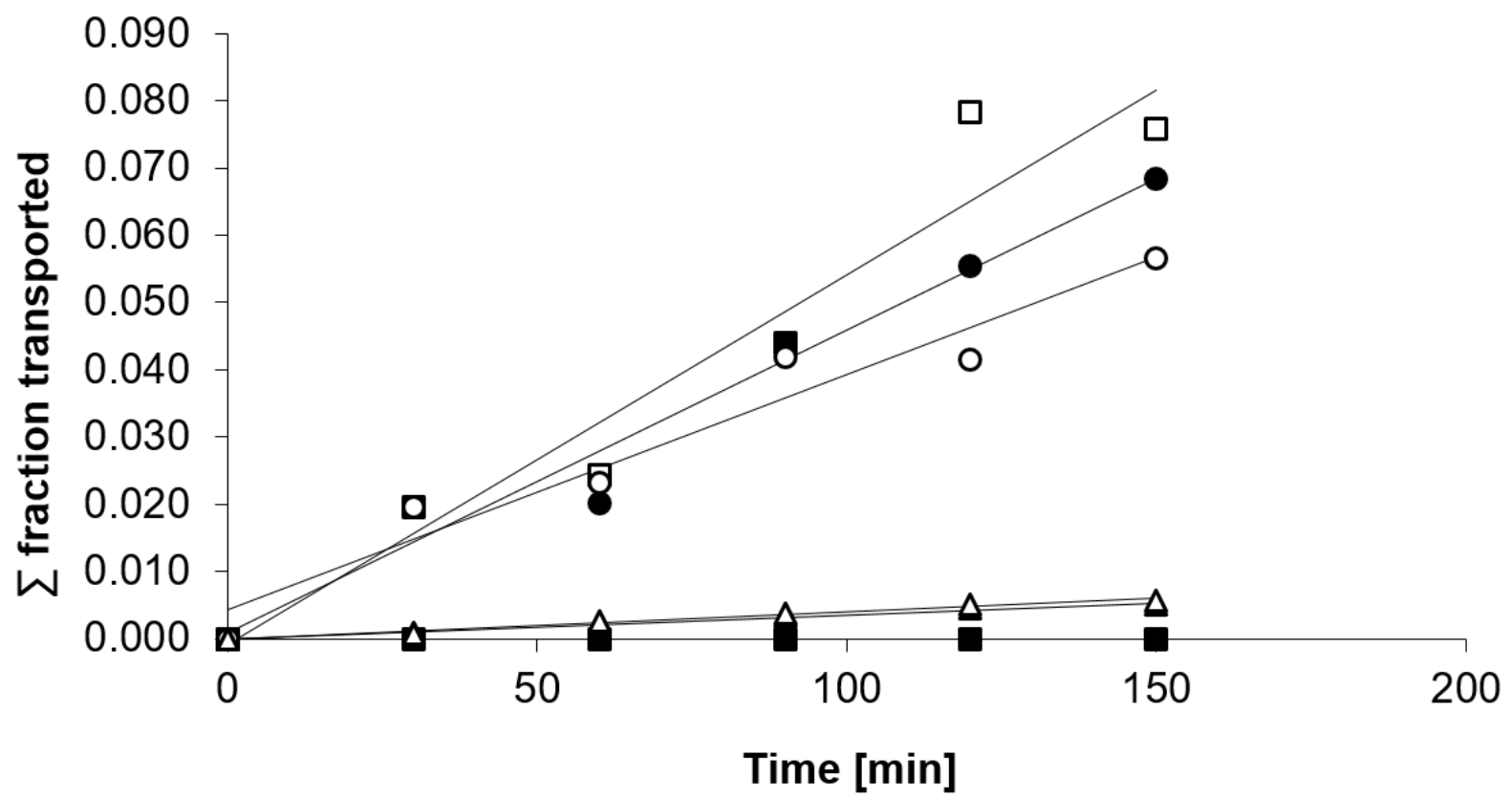


Figure S9: Fraction transferred vs time $(\min )$ for the replicate wells in the B-A Caco-2 permeability of 6-Dehydrochamaeliroside A (6).

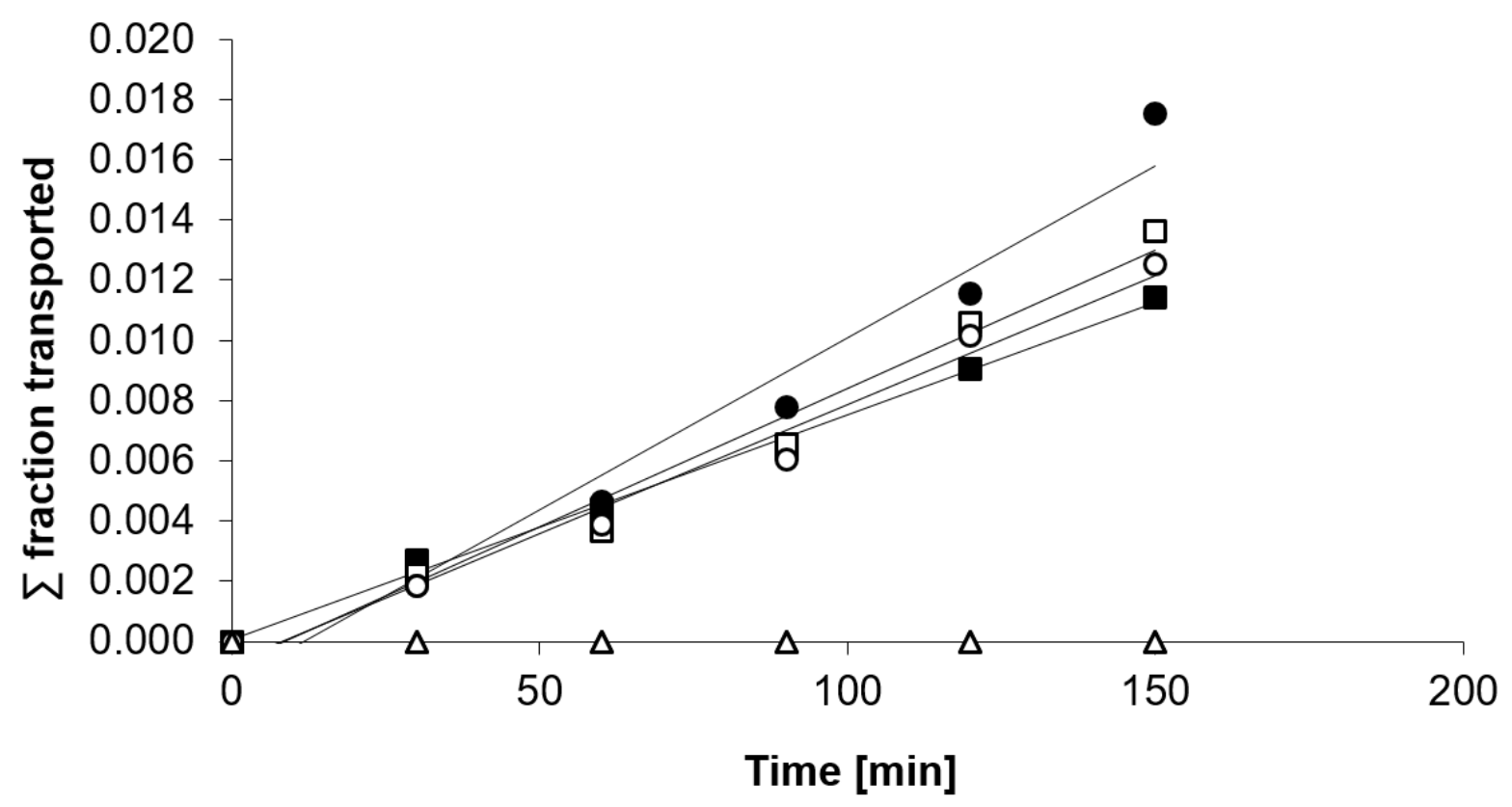

Figure S10: Fraction transferred vs time (min) for the replicate wells in the A-B Caco-2 permeability of 6-Dehydrochamaeliroside B (6).

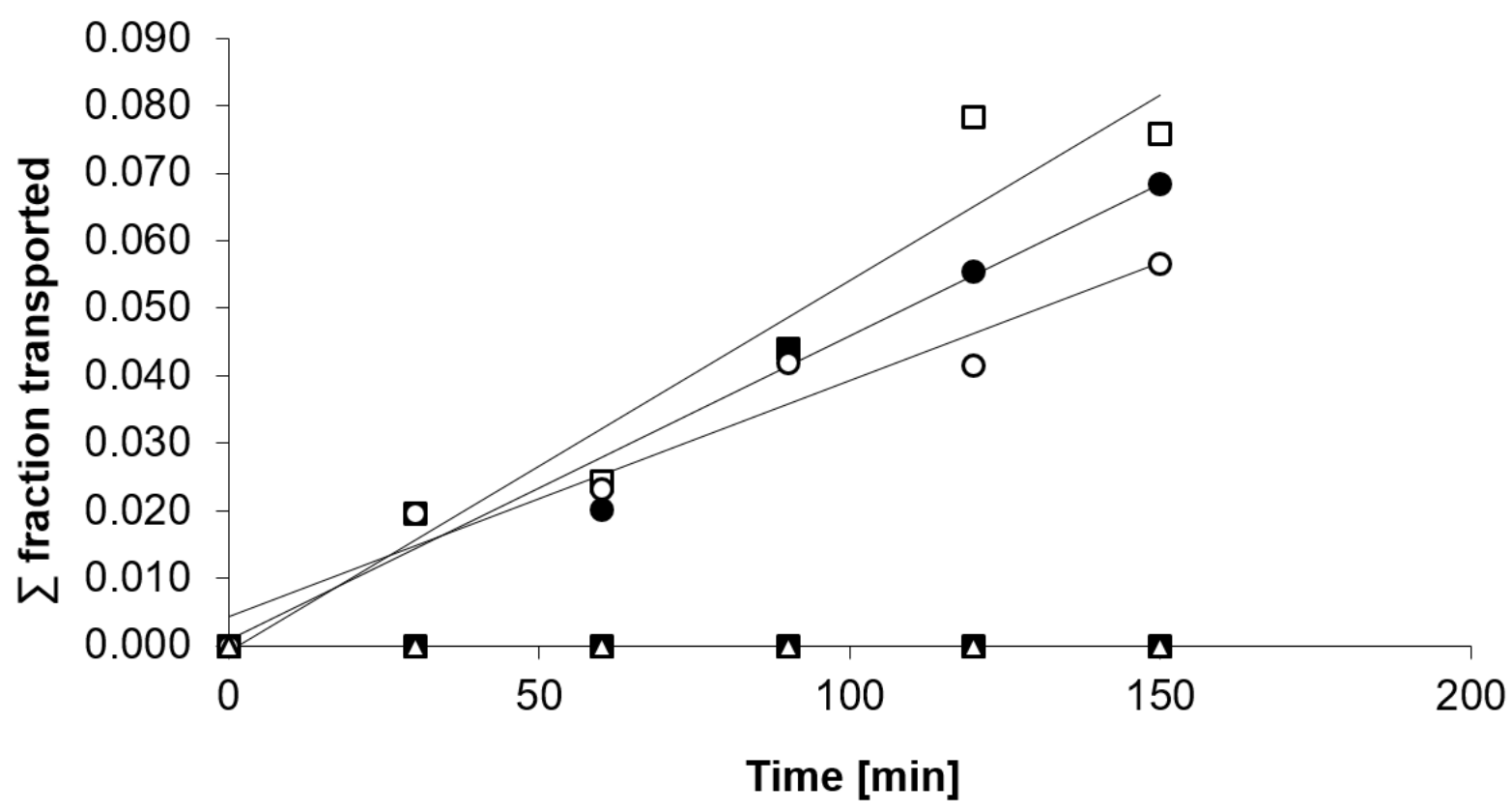


Figure S11: Fraction transferred vs time (min) for the replicate wells in the A-B Caco-2 permeability of Chamaeliroside E (7).

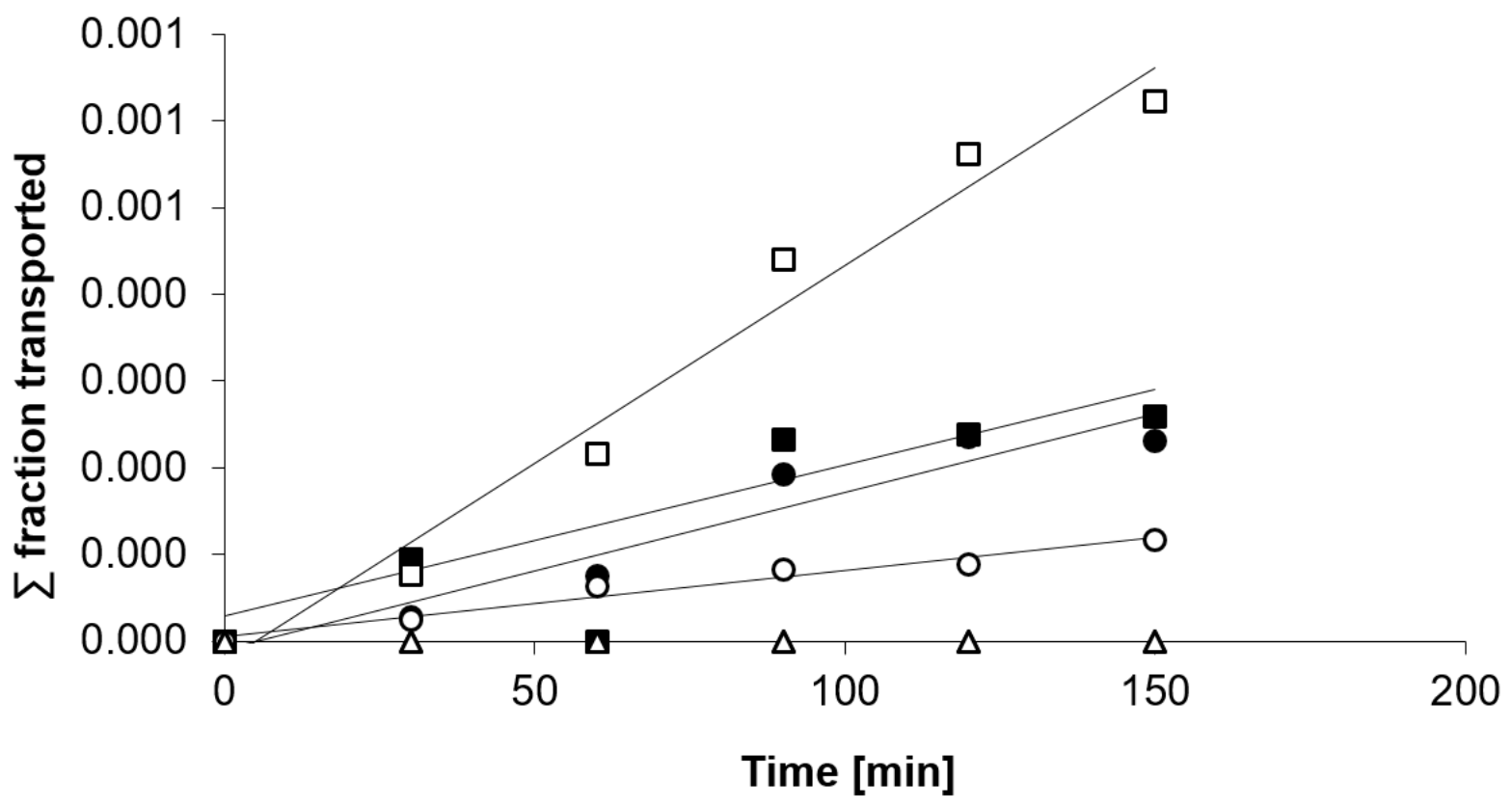

Figure S12: Fraction transferred vs time (min) for the replicate wells in the A-B Caco-2 permeability of Propranolol assay 1.

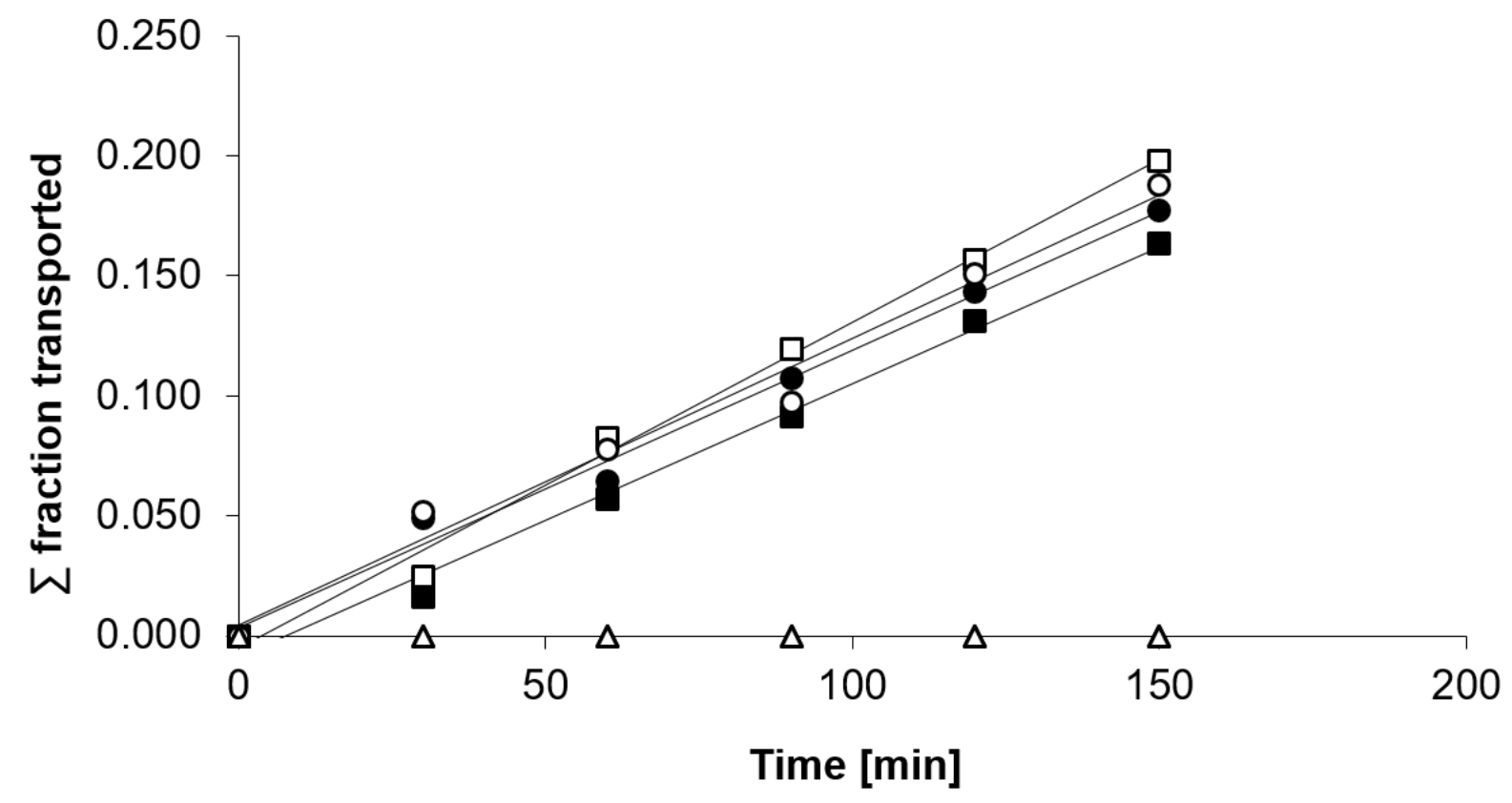


Figure S13: Fraction transferred vs time (min) for the replicate wells in the A-B Caco-2 permeability of Propranolol assay 2.

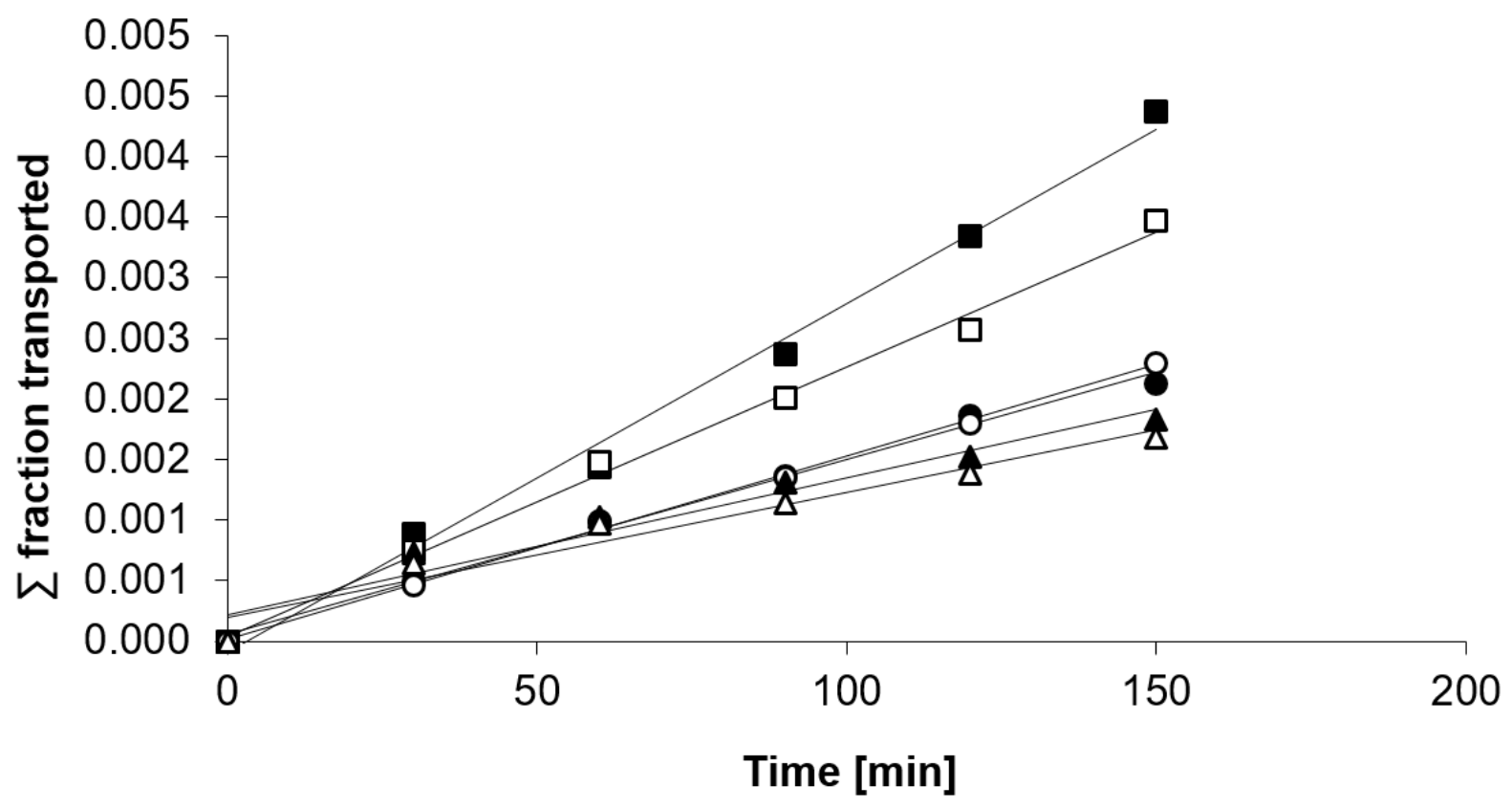

Figure S14: Fraction transferred vs time $(\mathrm{min})$ for the replicate wells in the B-A Caco-2 permeability of Propranolol assay 2.

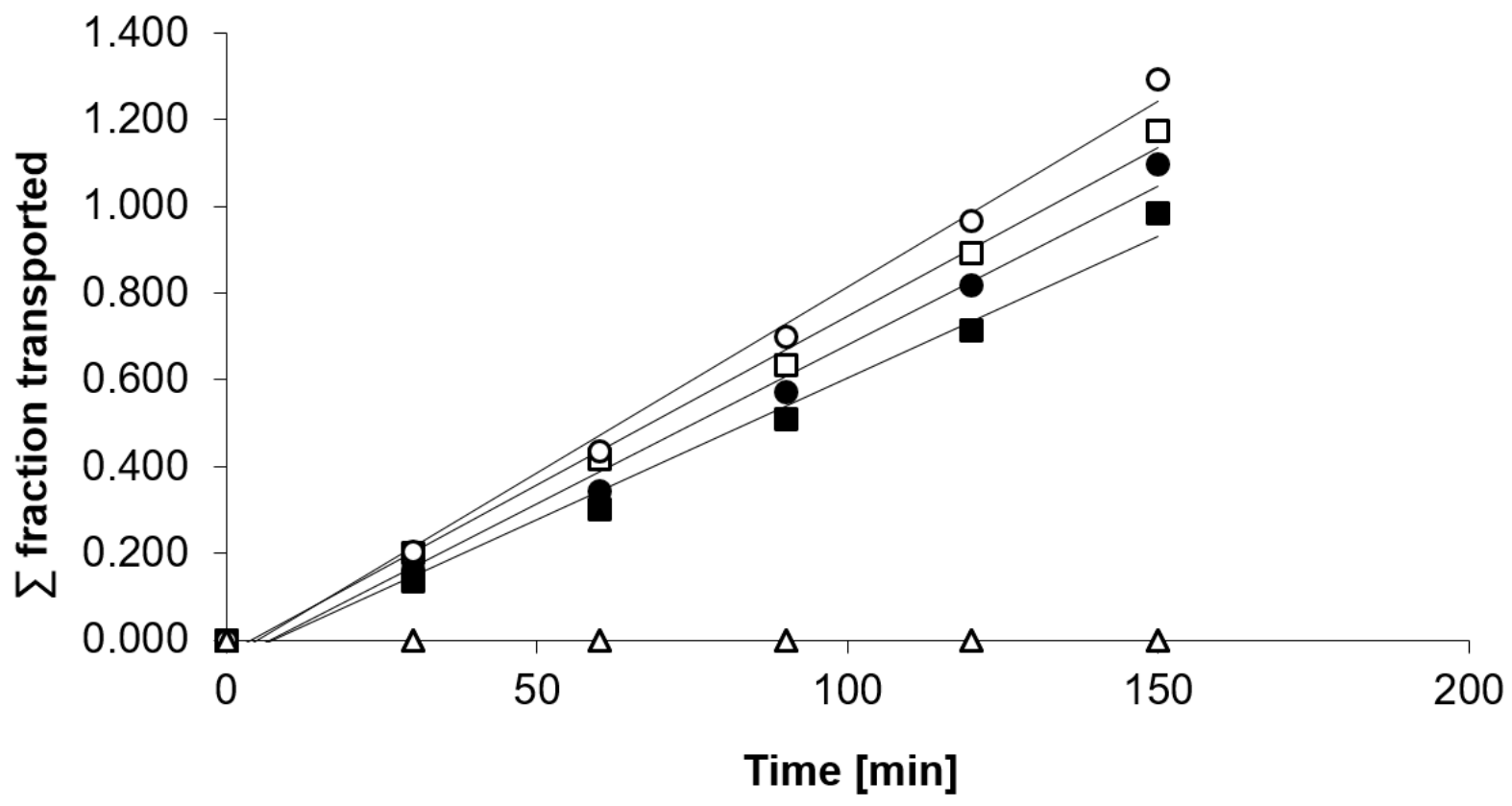


Figure S15: Fraction transferred vs time (min) for the replicate wells in the A-B Caco-2 permeability of Fluorescein assay 1.

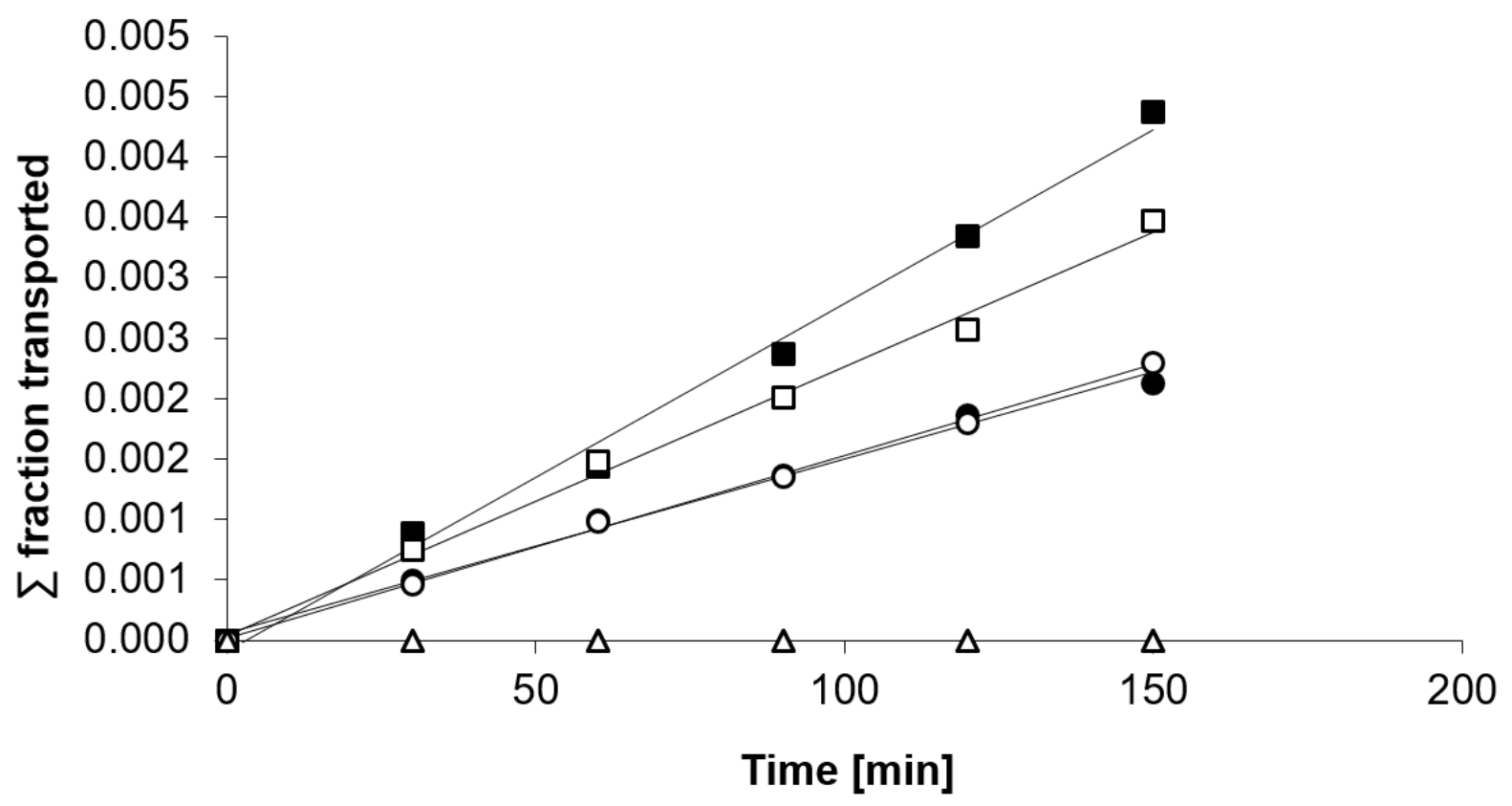

Figure S16: Fraction transferred vs time (min) for the replicate wells in the A-B Caco-2 permeability of Fluorescein assay 2.

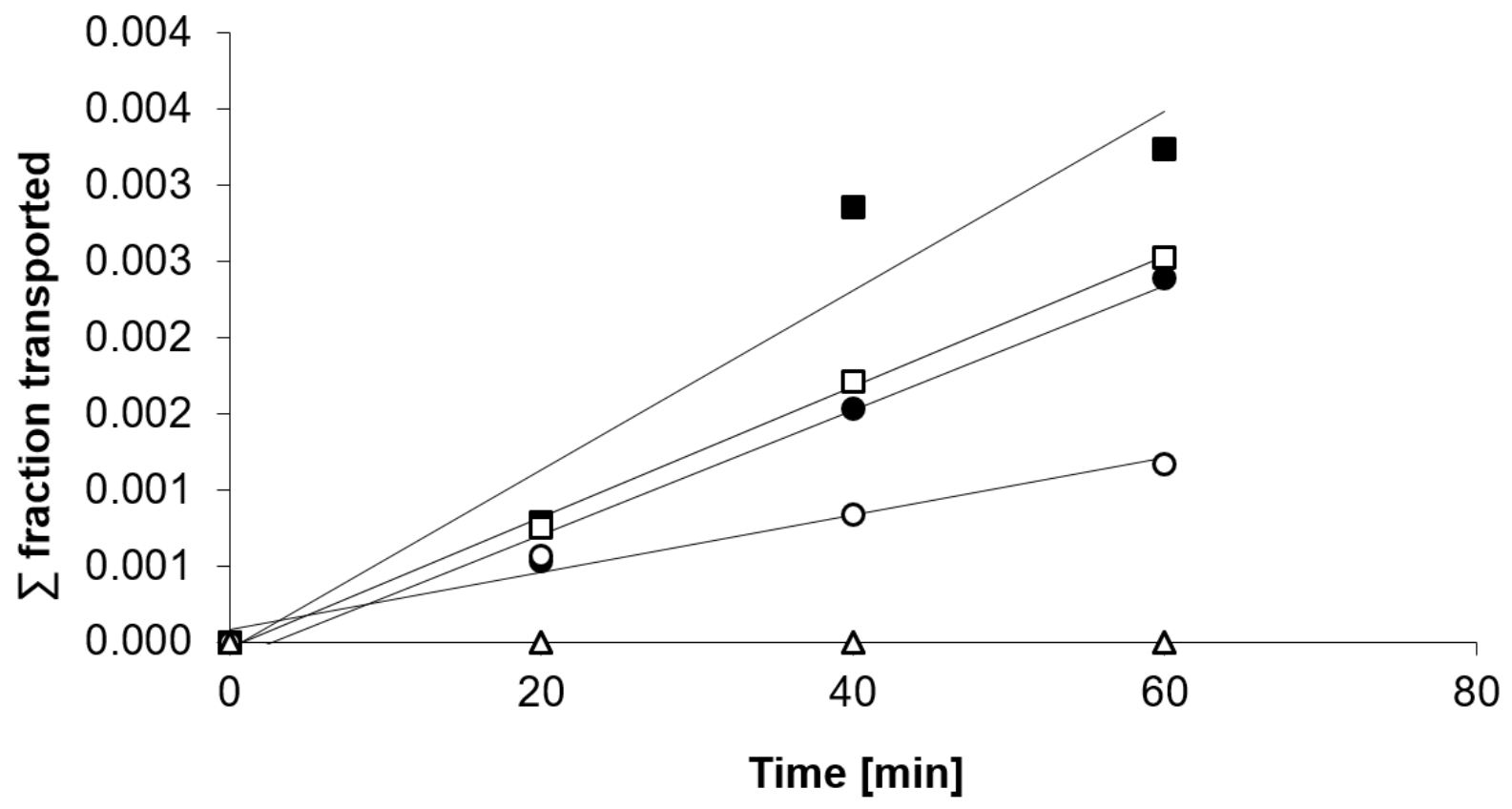

